\title{
Training and Promotion: Allocation of Skills or Incentives?
}

\author{
EDUARDO MELERO*
}

\begin{abstract}
This paper analyzes the impact of training on the probability of promotion. Results from the British Household Panel Survey indicate that training increases the probability of promotion of female workers, but not that of male workers. In terms of wages, men obtain significant returns from (general and specific) training acquired with their current employer, while women profit from general training. Overall, results suggest that career moves of women are importantly affected by the market value of their skills, while those of men fit better a model of promo tions as providers of incentives.
\end{abstract}

\section{Introduction}

CAREER DYNAMICS OF WORKERS WITHIN ORGANIZATIONS IS A WIDELY STUDIED TOPIC (see Gibbons and Waldman 1999a). Two topics are dominant in most analyses of career moves: efficiency in the allocation of skills to tasks and the incentive effect of rewarding good performance with a promotion. This article evaluates the importance of each of these two issues on the careers of men and women by investigating the effect of training on their prospects of a career move. Efficiency considerations in the allocation of skills are frequently assumed to drive employers' promotion decisions. In such cases, workers receiving job-related training are likely to be favored in promotion decisions. On the other hand, promotion systems may be used by firms to elicit effort from non-top level employees. Although such effort may include the learning of firm-specific skills, it is often exclusively associated with working hard. To evaluate the

* The author's affiliation is Department of Business Administration, Universidad Carlos III de Madrid, Spain. E-mail: eduardo.melero@uc3m.es. I am grateful to Mike Bognanno, Mark Bryan, Pascal Courty, Thomas Dohmen, Manuel F. Bagüés, Maia Güell, Miguel Ángel Malo, Peter Mueser, Jaime Ortega, Neus Palomeras, Eduardo Rodes, Trond Petersen (editor), and three anonymous referees for their helpful comments on earlier drafts of this work. Financial support under Grants SEJ2006 01731 and CSD2006 16 (Spanish Government) and S2007/HUM-0413 (Madrid Regional Government) is gratefully acknowledged. The data used in this article were made available through the ESRC Data Archive. The data were originally collected by the ESRC Research Centre on Micro-social Change at the University of Essex (now incorporated within the Institute for Social and Economic Research). Neither the original collectors of the data nor the Archive bear any responsibility for the analyses or interpretations presented here. 
empirical validity of these two different views of promotions, I draw on data from twelve waves of the British Household Panel Survey (BHPS, 19912002) to investigate how employees' job-related training affects their chances of improving their careers. The results show substantial differences in the patterns of career moves of men and women. Female workers' moves are significantly affected by their training activities and their wages are attached to the market value of their skills. Therefore, a model of careers focused on assignment of skills fits well their paradigm. Conversely, men's promotions are more affected by effort than by training activities, and only the training carried out with their current employer affects their wages. This suggests that male workers select into career tracks in which promotion rules are designed to induce effort.

To the best of my knowledge, the only empirical work published to date which includes training as a determinant of promotion is Pergamit and Veum (1999). They use the 1989 and 1990 samples from the American National Longitudinal Survey of Youth to analyze the causes and consequences of promotion. They find that company training and prior career moves are particularly important predictors of promotion. Their study, however, only includes cross-sectional estimators, since the specific questions about job changes were not part of the longitudinal questionnaire. Other articles that analyze the determinants and consequences of promotions are Sicherman and Galor (1990) and McCue (1996), using the Michigan Panel Study of Income Dynamics for the periods 1976-1981 and 1976-1988 respectively, and Francesconi (2001), using the BHPS for the 1991-1995 waves. All these studies provide descriptions of what type of workers are more likely to obtain promotions. They find that young employees working in large establishments, holding high-level positions, working long hours, and having recently changed jobs have higher probability of promotion. Most of the knowledge regarding career paths, however, comes from single-firm evidence. Particularly, Baker, Gibbs, and Holmstrom (1994) identify some stylized facts about task assignment and careers, namely: high correlation between measured productivity and promotion prospects, (partial) attachment of wage growth to promotions, low frequency of demotions, serial correlation of wage increases and promotions, and the existence of fast tracks. ${ }^{1}$ Some succeeding articles replicate Baker, Gibbs, and Holmstrom's (1994) study in other organizational contexts and obtain similar findings, although it is not clear whether the described results remain statistically significant once individual characteristics are accounted for (Ariga, Ohkusa, and Brunello 1999; Dohmen, Kriechel, and Pfann 2004; Seltzer and Merrett 2000;

\footnotetext{
${ }^{1}$ The concept of fast track refers to the observation that workers who have been promoted faster than their colleagues to a given level in the hierarchy of a firm tend also to be promoted faster to the next level.
} 
Treble et al. 2001). The subsequent building of theoretical models of careers in organizations has tried to accommodate these results in terms of allocation of skills (Gibbons and Waldman 1999a).

This paper extends the empirical literature on career dynamics in three important aspects. First, it offers a specific focus on the relationship between training and promotion that is useful to evaluate different theories of careers. Second, performing the analysis separately for men and women allows us to assess whether sex differences in career outcomes can be explained in terms of a single theory. Finally, unlike previous research, this article presents an analysis of determinants of promotion that controls for time-invariant unobserved heterogeneity for a representative sample of workers. The article is organized as follows: in the next section, I provide a summary of the relevant theories dealing with promotions in organizations; in the third section, I analyze empirically the effect of job-related training and other relevant variables on the career progress of male and female workers; in the fourth section, the analysis is repeated, first separately considering different types of training and then splitting the sample by education and occupation groups; and the last section deals with the discussion of results and conclusions.

\section{Background}

Much theoretical literature has dealt with task assignment and career paths of workers within firms (Gibbons and Waldman 1999a). Despite the particularities of each contribution, three broad groups of theories can be distinguished: theories that rely on human capital accumulation and gradual learning of workers' abilities, theories concerned with the role of promotions in inducing the accumulation of firm-specific human capital, and theories that view promotions as providers of incentives to work hard. All of them are briefly described below.

Promotions may be the natural consequence of the acquisition of skills that are more productive at higher-responsibility jobs. Suppose that the potential career of a worker is defined by a hierarchy of different jobs, so that productivity is more sensitive to skills in upper-level jobs than in lower-level jobs. Then, a worker is promoted to the next job of the hierarchy when his set of skills exceeds the minimum level that makes efficient the re-assignment. Accordingly, job-related training should lead to higher probabilities of promotion as long as it increases a worker's skills. The most comprehensive version of this approach is the model by Gibbons and Waldman (1999b, 2006). They consider the productivity of workers as a complementary combination of individual ability (learned progressively by the market) and the human capital 
obtained through working experience. They obtain a set of predictions that fit well Baker, Gibbs, and Holmstrom's (1994) findings.

Other theories depict "promotion schemes" as contracts designed to provide incentives for firm-specific human capital accumulation, rather than being the consequence of such accumulation (Carmichael 1983; Prendergast 1993). Because of problems of appropriation, workers are typically reluctant to invest in firm-specific training. For this reason, employers may commit to promotion rules that provide incentives to do it, even if this is suboptimal from the point of view of task allocation. According to these models, wages should be highly attached to jobs and returns to specific training should depend critically on promotion achievement.

A related stream of literature emphasizes the advantages of using promotions as incentives to work hard. Lazear and Rosen (1981) first formalize the idea of promotions as prizes of rank-order tournaments. They stress the particular value of tournaments when there are external factors affecting the productivity of all workers and rank is easier to observe than an individual's productivity. Problems posed by the potential unbalance in the quality of candidates can be addressed with the combination of handicaps and external competition (Chan 1996). The commitment to relocate promoted workers to higher-responsibility jobs attenuates problems of bribery and other influence activities that arise in subjective evaluation systems (Fairburn and Malcomson 2001). Finally, complementing competitive promotions with the commitment to fire un-promoted workers ("up or out" contracts) eliminates employer's incentives to underreport the productivity of employees (Kahn and Huberman 1988). Firms that operate as internal labor markets are frequently argued to use promotions as incentive devices (Doeringer and Piore 1971; Fairburn and Malcomson 2001). These organizations tend to recruit employees only at the lowest levels, reserving higher-level positions for promoted insiders. Without the threat of outside competition, promotion prospects become a principal source of incentives in these firms.

These different views of within-firm career moves are to some extent compatible. A firm that fills job vacancies through promotions in order to better allocate the skills of its workers can also devise promotion rules that encourage hard work or specific investments. Nevertheless, the determinants and consequences of workers' promotions will differ according to the relative importance of efficient task-assignment and incentive concerns. The purpose of this article is the study of such differences in determinants and consequences of promotions, in terms of training and wage growth, respectively. If promotions are the result of re-assignments of workers' (expected) skills, job-related training must increase promotion probability. Moreover, if training investment decisions are related to positive updates of market beliefs of worker's ability, 
the decision itself will be correlated with higher promotion prospects. According to this view, wage returns to training will also be larger when promotion is awarded, since the acquired skills are more efficiently exploited in the new job. Conversely, if promotions are just rewards to hard work, they must be significantly associated with indicators of effort such as overtime work. In this case, job-related training or other forms of human capital accumulation will be unimportant for promotion and returns to training should be independent of promotion achievement. Finally, if promotion systems are devised to encourage workers to make firm-specific investments, the distinction between general-purpose and firm-specific human capital is crucial for the analysis of the relationship between training and career moves. In particular, the provision of specific training must be especially related to promotion chances, the observed returns to specific training must decrease considerably when promotion is controlled for, and the interaction effect of specific training and promotion on wages must be positive. The different predictions that these theories foretell about the relationship among training, promotion, and wage growth are summarized in Table 1.

Theories of task assignment and career paths are also at the heart of rationalization of differences in labor market outcomes across population groups. Differences between men and women in career development and wage growth

\section{TABLE 1}

Predictions from the Different Theories on Promotions

\begin{tabular}{|c|c|c|c|}
\hline & Assignment of skills & Incentives to effort & Incentives to invest \\
\hline $\begin{array}{l}\text { Effect of training on } \\
\text { promotion probability }\end{array}$ & Positive effect & No effect & Positive \\
\hline $\begin{array}{l}\text { Effects of training and } \\
\text { promotion on wages }\end{array}$ & $\begin{array}{l}\text { Positive and possibly } \\
\text { complementary effects }\end{array}$ & $\begin{array}{l}\text { Independent } \\
\text { positive effects }\end{array}$ & $\begin{array}{l}\text { Returns to training } \\
\text { partially offset by } \\
\text { promotion } \\
\text { Complementary effects }\end{array}$ \\
\hline $\begin{array}{l}\text { Differences between general } \\
\text { and specific training on } \\
\text { promotion probability }\end{array}$ & No differences & $\begin{array}{l}\text { No differences } \\
\text { (no effect) }\end{array}$ & $\begin{array}{l}\text { Only specific training } \\
\text { matters for promotion }\end{array}$ \\
\hline $\begin{array}{l}\text { Differences between general and } \\
\text { specific training in their } \\
\text { effect on wages }\end{array}$ & $\begin{array}{l}\text { No difference in the } \\
\text { effects of general and } \\
\text { specific training }\end{array}$ & $\begin{array}{l}\text { No difference in } \\
\text { the effects of } \\
\text { general and } \\
\text { specific training }\end{array}$ & $\begin{array}{l}\text { Returns to training } \\
\text { (partially) offset by } \\
\text { promotion achievement } \\
\text { Complementary effect } \\
\text { of specific training and } \\
\text { promotion on wages }\end{array}$ \\
\hline Other predictions & & $\begin{array}{l}\text { Proxies for effort } \\
\text { should affect } \\
\text { promotion } \\
\text { probabilities }\end{array}$ & \\
\hline
\end{tabular}


are a particularly interesting case, since theoretical approaches dealing with them are usually based on the models described above. Lazear and Rosen (1990), for example, argue that female workers have poorer career outcomes because their higher non-market opportunities make less profitable their allocation to higher-level jobs. Likewise, stronger family commitments could make overtime work relatively more costly for women, so that they would find themselves in a "mommy track," with lower advancement prospects. Alternatively, Booth, Francesconi, and Frank (2003) argue that promotions are devised to induce investments in firm-specific human capital and operate similarly for men and women. After promotion, however, female workers may suffer from discrimination in the form of worse outside offers and lower propensity of incumbent employers to match offers. In that case, women would have equal or higher promotion chances than men, but they would obtain lower wage increases upon promotion. Booth, Francesconi, and Frank (2003) and Hersch and Viscusi (1996) provide evidence consistent with this rationale.

These theories, either based on incentives or value of skills, rely on the assumption that organizations' promotion logics are equal for men and women. This implies that the factors that affect promotion prospects have similar effects on workers of both genders. Yet, if men and women differ in their expected attachment to their employers or to the job market in general, the forces that shape their career progress can also be expected to diverge. This can be due either to selection into different occupations (Polachek 1981) or to selection into different paths within the same occupation. By analyzing how training and other work-related variables affect promotion probability and wage growth for both genders, this article sheds light on (1) whether careers of men and women are comparable at the population level and if so, (2) which theory explains better gender differences in labor market outcomes.

\section{Evidence on Training, Careers, and Wages}

One of the most direct ways to evaluate how workers' human capital affects their career progress is to investigate whether the job-related training affects career moves. The analysis presented in this section includes, first, the estimation of how (internal and external) promotion probability is affected by training and other job-related variables and, second, the study of the extent to which wage returns to training depend on promotion.

Data. The sample of employees used for this research includes all not selfemployed workers interviewed in the BHPS during the period 1991-2002, who were between 16 and 64 years old, working neither in the public sector 
nor in the armed forces, and with valid recorded data for all the variables of interest. The result of such selection is an unbalanced panel of 37,140 observations from 7894 individuals. Population means of the most important variables can be found in the Appendix. It is remarkable that women are reported to earn wages around 27 percent below those of men (similar to the raw wage gap typically calculated for the UK) ${ }^{2}$ and that they obtain significantly fewer internal promotions on average than men (6.4 percent of female workers achieve an internal promotion each year while up to 8 percent of males obtain it). ${ }^{3}$ Such a gap is not found in quits for better jobs, where sex differences are almost inexistent (8.6 percent of female workers and 8.9 percent of males quit their firms for a better job each year).

Methodology. To study determinants of promotions, I use the job history data recorded in the survey jointly with job-related individual questions. Each year, individuals are asked about any change in their job status and, if they are no longer doing the job reported in the previous year, they are asked about the type of transitions done (see Taylor et al. 2001). I use the answers to these questions to create a dichotomous variable registering the event of a "promotion with current employer" between year $t$ and year $t+1$ whenever a worker states, in the interview at $t+1$, that (1) he has stopped doing the job that he was doing at $t$, that (2) he has started doing a different job for the same employer, and that (3) such job change was a promotion. An analogous variable tags whether the worker quits his job with his previous-year employer between $t$ and $t+1$ for a better job elsewhere. As for the data on wages, it is directly computed from the information contained in each year's survey on working income and worked hours. Job-related training is selfreported by the employees by giving a positive answer to the question "Have you taken part in any training as part of your present employment in the last year?"4 There is a potential problem of reverse causality in that promotion may itself involve the provision of further training to get started in the new job. To attenuate it, ${ }^{5}$ promotion between $t$ and $t+1$ is analyzed in relation to a set of individual and job characteristics observed at $t$. The main variable of

\footnotetext{
${ }^{2}$ See, for example, Perfect and Hurrell (2003).

${ }^{3}$ Booth, Francesconi, and Frank (2003) did not find such strong difference in their analysis. The mismatch is likely to be due to the fact that they focused only on full-time workers, while the present work also includes employees working less than 30 hours a week.

${ }^{4}$ The training question was changed after the eighth wave to "Have you taken part in any training (other than regular education) schemes or courses at all last year or completed a course of training which led to a qualification?" Strong similarities in descriptive statistics suggest that workers' understanding of the question did not change.

${ }^{5}$ Note that it is not possible to completely eliminate the potential reverse causation problem, as firms could systematically offer training to workers whose promotion has been decided 2 or 3 years in advance.
} 
interest is then training received by the worker between $t 1$ and $t$, measured both in terms of events and intensity. ${ }^{6}$ The drawback of doing this is that some of the training may have an immediate effect on the probability of obtaining a promotion. Since this effect may not be reflected in next year's promotion outcomes, the estimated effects may suffer a bias towards zero. Another potential problem is the exogeneity of the training measure. As the Appendix shows, training receivers differ from non-receivers in several observable characteristics. They tend to be younger, less experienced, and more educated employees. Analogously, there may be some unobserved characteristics affecting both training and career prospects of workers. The most important ones, such as individual ability, are time-invariant and are eliminated in fixed-effects estimations.

Since the analysis of this paper focuses on both dichotomous outcomes (career moves) and continuous dependent variables (wages), both qualitative and standard regression analyses are carried out. The panel nature of the BHPS allows accounting for unobserved effects in the estimation of probability of promotion and the determinants of wages. In particular, the following model is considered for promotion prospects:

$$
\begin{gathered}
P_{i j t+1}^{*}=X_{i j t}^{\prime} \beta^{P}+T_{i t}^{\prime} \alpha^{P}+Y_{t}^{\prime} \delta^{P}+\mu_{i}^{P}+v_{i j}^{P}+\varepsilon_{i j t}^{P} \\
\text { with } \quad P_{i j t+1}=0 \quad \text { if } \quad P_{i j t+1}^{*} \leq 0 \text { and } \quad P_{i j t+1}=1 \quad \text { if } \quad P_{i j t+1}^{*}>0
\end{gathered}
$$

where $P_{i j t+1}$ is a dummy variable that takes value 1 if individual $i$ has been promoted by his current employer $j$ between $t$ and $t+1$ and 0 otherwise. $P^{*}{ }_{i j t+1}$ is an unobserved latent variable representing "promotions prospects." Job-related training received by the employee is captured by $T_{i j t} . Y_{t}$ is a vector of year-specific dummies accounting for common time trends and $X_{i j t}$ is a set of control variables including individual characteristics such as education, firm seniority, job market experience, and overtime work done; firm characteristics such as size, industry, region, and degree of unionization; and job characteristics such as type of contract, bonus payments, part-time status, and managerial responsibilities. The variance in promotion prospects not explained by observable characteristics is divided into an individual fixed component $\mu^{P}{ }_{i}$, a workeremployer match effect $v^{P}{ }_{i j}$, and a transitory shock $\varepsilon^{P}{ }_{i j t}$.

\footnotetext{
${ }^{6} \mathrm{I}$ interpret the results assuming that both employers and employees are involved in the effort to increase workers' human capital. The BHPS specifies who provides and formally pays the costs of job-related training only for the sub-sample 1998 2002. For these last 5 years, the figures show that in 87 percent of cases there is involvement in the provision of training by the employer in one way or another.
} 
The efficiency of the estimation can be improved through the integration of $\mu_{i}$ as random. However, if such individual effects are correlated with the explanatory variables, a fixed-effects approach is needed to obtain consistent estimates of time-variant variables. It is possible that unobserved variables, such as motivation of the worker, personality traits, natural ability, or quality of the match with the employer affect both the promotion chances of an individual and the incidence of training. Therefore, I estimate the probability of a career move using a logit model, which is the only non-linear model that allows obtaining consistent estimates through a fixed effects approach (Chamberlain 1980). The lack of firm identifiers in the BHPS makes impossible to take explicitly into consideration the employee-employer match effects represented by $v_{i j}$. I address this point in a similar fashion to Booth and Bryan (2007), by introducing a set of dummy variables accounting for each workeremployer match in the case of fixed-effects specifications. ${ }^{7}$

Results: Probability of a Career Move. In this subsection, the results from estimating different versions of equation (1) are presented. I explore both random-effects and fixed-effects specifications to estimate the probability of obtaining internal promotion (versus not obtaining it). In the random effects specification, I include an additional control variable indicating whether the worker received a promotion in the previous year. This is done to attenuate the potential bias caused by unobserved characteristics under such specification (Heckman and Borjas 1980; Pergamit and Veum 1999). The logit fixed-effect model (Chamberlain 1980) is based on a "within-group" approach, where time-invariant explanatory variables are eliminated from the estimation. The analysis of the probability of quitting for a better job (versus not doing it) is done analogously. It is particularly likely that time-invariant unobserved characteristics such as personality traits and natural ability affect both training and promotion. Therefore, the less efficient but consistent fixed-effects specification is more reliable that the random-effects specification when results from both models strongly diverge.

Table 2 presents the odds-ratio estimates obtained from the logistic regressions of the probability of obtaining a career improvement move with either the current employer (i.e., promotion), or a different one (i.e., quit for better job). The figures represent how an increase in each of the explanatory

\footnotetext{
${ }^{7}$ The design of this set of variables is as follows: A first dummy takes the value 1 if the worker remains with his first employer since he entered the sample and switches to 0 when such an employment spell is finished. Then, a second dummy takes the value 1 if an employee has switched employers once since the first match and maintains such unitary value if he keeps on working for this second match. Otherwise, this second variable takes the value 0 . Such process is repeated until producing up to nine dummy variables.
} 


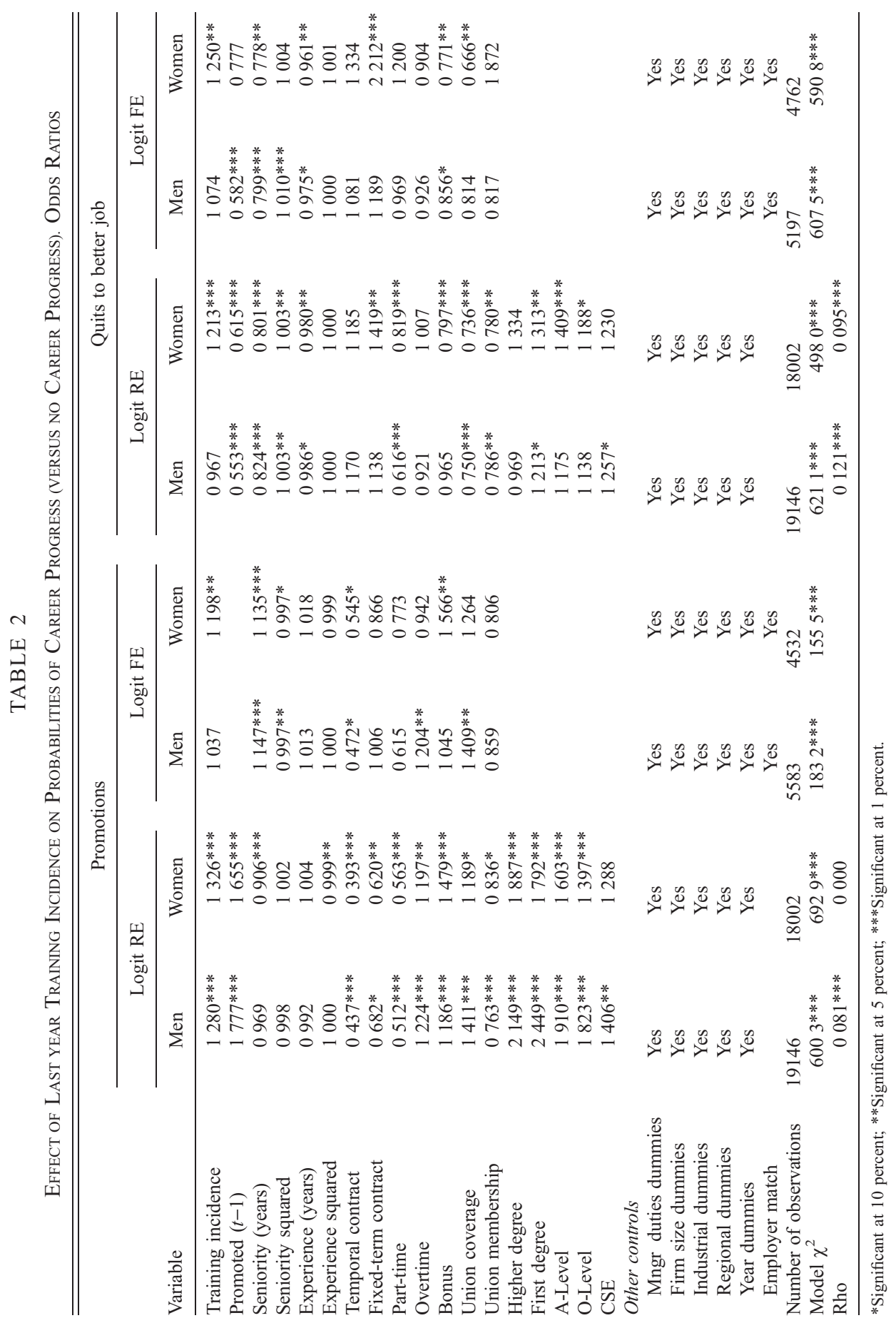


variables multiplies the odds favoring the change. ${ }^{8}$ A positive (negative) effect on the probability is associated with an odds-ratio greater (lower) than one.

As Table 2 shows, the incidence of training in the previous year has a significant positive effect on promotion chances for both men and women in the random-effects specification. In the fixed-effects model, however, the oddsratio drops to non-significant levels for men, while it is only slightly reduced for women. ${ }^{9}$ Training slightly decreases the probability of switching employers for the sample of male workers while increasing the chances for the sample of women, although the effect is significant for this last gender group only. The effect on promotion of other variables usually associated with human capital, such as job market experience or firm seniority, is also strongly affected by the presence of unobserved heterogeneity. Chances of promotion decrease with firm seniority for both male and female workers in the random-effects specification. Controlling for individual fixed effects, however, causes the relationship to take an inverted U-shape for both genders, with odds of promotion increasing during approximately the first 2 years and decreasing afterwards. Previous job market experience does not seem to have any significant effect on promotion. The odds that a worker switches employers to a better position strongly decreases with seniority and, to a lower extent, with experience with previous employers. Table 2 also shows the effect of other job-related characteristics on the probability of promotion. As predicted by a view of promotions based on incentives, both overtime work and part-time status have strong impacts, positive and negative respectively, on promotion chances. It is remarkable, however, that the estimated effects decrease to non-significant levels for the sample of female workers when we control for unobserved heterogeneity.

Table 3 shows the effect of training on career progress for different alternative measures of training incidence and intensity in the last 2 years. The results follow similar patterns for all the different measures. In all cases the positive effect decreases to non-significant levels for the sample of men when we control for fixed-effects, while it remains relatively large and significant for the sample of women. The effects are larger if one considers all the training received in the last 2 years, suggesting that the impact on internal career

\footnotetext{
${ }^{8}$ Odds-ratios have been presented instead of marginal effects at the mean because the latter are sensitive to the distribution of individual effects. Since Conditional (fixed-effects) Logit does not allow one to compute the individual effects, it is not possible to know their true distribution, nor to obtain the corresponding marginal effects. On the other hand, Odds-ratio estimates from the logit model are constant across all the values of other variables.

${ }^{9}$ These results follow a similar pattern to those of Pergamit and Veum (1999): in their Probit analysis of the probability of promotion as a function of the training received in the previous year, they found that the effect was larger for women than for men and that the effect found for the sample of men was not statistically significant.
} 
TABLE 3

Effect of Last 2 Years, Training Incidence and Intensity on Career Progress

(Versus no Career Progress). Odds Ratios ${ }^{\mathrm{a}}$

\begin{tabular}{|c|c|c|c|c|c|c|c|c|}
\hline \multirow[b]{3}{*}{ Variable } & \multicolumn{4}{|c|}{ Promotions } & \multicolumn{4}{|c|}{ Quits to better job } \\
\hline & \multicolumn{2}{|c|}{ Logit RE } & \multicolumn{2}{|c|}{ Logit FE } & \multicolumn{2}{|c|}{ Logit RE } & \multicolumn{2}{|c|}{ Logit FE } \\
\hline & Men & Women & Men & Women & Men & Women & Men & Women \\
\hline Incidence last year & $1.280^{* * *}$ & $1.326^{* * *}$ & 1.037 & $1.198^{* *}$ & 0.967 & $1.213 * * *$ & 1.074 & $1.250^{* *}$ \\
\hline Days last year & 1.001 & $1.003 * *$ & 0.999 & $1.004^{* *}$ & 0.998 & 1.001 & $0.996 * *$ & 1.001 \\
\hline Incidence last 2 years & $1.388 * * *$ & $1.432 * * *$ & 1.106 & $1.260^{* *}$ & $0.882 *$ & 1.088 & 0.928 & 1.114 \\
\hline Days last 2 years & $1.002 * *$ & $1.003 * * *$ & 1.000 & $1.003 * *$ & 0.999 & 1.001 & 0.999 & 1.001 \\
\hline
\end{tabular}

${ }^{a}$ All regressions include the same control variables of the analogous regressions summarized in Table 2 .

*Significant at 10 percent; $* *$ Significant at 5 percent; $* * *$ Significant at 1 percent.

prospects may be persistent over time. The effect of training on the probability of quitting for a better job is positive for women and negative for men for most measures of training, but coefficients are almost never significant for this dependent variable.

Even after controlling for individual fixed effects, the results presented in Tables 2 and 3 could be biased in the presence of time-variant unobserved heterogeneity or dynamic interactions (see Wooldridge 2002). The positive effect of promotion on further training observed in Pergamit and Veum (1999) and the serial correlation in promotion rates caused by the existence of fast tracks (Gibbons and Waldman 1999a) ${ }^{10}$ suggest that this could be the case. To address this issue, I also estimate equation (1) as a linear probability model, where the effects of the key explanatory variables are estimated using their lagged values as instruments in a GMM procedure (Arellano and Bond 1991; Wooldridge 2002). As shown by Ahn, Lee, and Schmidt (2001), the GMM model accounts for time-variant individual unobserved effects as long as they follow a common temporal pattern. The results, not reported here, show effects qualitatively similar to those displayed for the fixed-effects specifications. In particular, the GMM linear estimator predicts that completing some training in a given year implies 2.5 percent and 2.9 percent increases in women's probability of internal promotion and quit for a better job, respectively, in the following year (around one-third of average probabilities). The same variables exhibit non-significant estimated effects of about 1.4 percent and 0.4 percent, respectively, for the case of men.

The positive effect of training on the probability of internal promotion found for the sample of women is consistent both with models of assignment of

\footnotetext{
${ }^{10}$ This second issue, however, will be less important as long as such serial correlation in wage probabilities is basically due to individual observable and unobservable characteristics rather than to true state-dependence, as reported in the recent literature (Belzil and Bognanno 2004; Dohmen, Kriechel, and Pfann 2004).
} 
skills and models of incentives to invest. In the case of male workers, the effect is surprisingly small and not significant for the within-group estimates. Furthermore, there is a significant effect of overtime work on promotion chances only for the group of men. Jointly, these results suggest a difference in the relevant driving forces underlying promotions of male and female workers. Promotions appear more related to measures of effort and commitment with the firm (in terms of working hours) in the case of male workers and to human capital accumulation (in terms of job-related training) in the case of females. In other words, female career moves depend more on the assignment of their skills while those of men appear more related to effort. The concave relationship between firm seniority and promotion observed for both genders in this paper as well as in most of the previous empirical literature (Francesconi 2001; Pergamit and Veum 1999) is, in principle, more consistent with models of assignment of skills than those about incentives. ${ }^{11}$ Nevertheless, such concavity could also reflect that organizational hierarchies are disproportionally narrower at higher levels. Since senior employees tend to hold higher-level positions within their organizations, they may face increasingly high promotion standards that partially offset the effect of their superior skills on their probability of promotion.

Results: Wage Returns to Training and Promotion. The joint analysis of wage returns to training and promotion is a complementary way to study career progress of workers in the context of the different existing strands of theories (see summary in Table 1). More generally, the observed correlation between training and promotion reported above suggests that researchers trying to estimate returns to training investments must account for position upgrade. Otherwise such returns could be largely reflecting a better assignment of workers' (new and old) skills. For analogous reasons, the estimation of wage increases upon promotion must account for training receipt.

The impact of training and promotion on workers' earnings is estimated in the form of the following regression model:

$$
\ln w_{i j t}=X_{i j t}^{\prime} \beta^{w}+P_{i j t} \theta^{w}+T_{i t}^{\prime} \alpha^{w}+P_{i j t} T_{i t}^{\prime} \gamma^{w}+Y_{t}^{\prime} \delta^{w}+\mu_{i}^{w}+v_{i j}^{w}+\varepsilon_{i j t}^{w}
$$

where $\ln w_{i j t}$ is the logarithm of the real hourly wage of individual $i$ with employer $j$ at time $t$ and the rest of the variables are as described in the previous subsection. I separately consider the training that individuals received while working for previous and current employers. In a similar fashion to

\footnotetext{
${ }^{11}$ Decreasing returns to training and decreasing rate of learning about workers' skills make very tenured workers less likely to be promoted. From the point of view of incentives, however, there is no clear reason to think that tenured workers should face lower probabilities of promotion than more junior employees.
} 
Booth and Bryan (2007), I consider all the training accumulated by the worker since his first year in the sample, in order to allow for higher flexibility in the estimation of the returns to training and reduce the bias caused by measurement error. Potential correlation of the observed explanatory variables with the unobserved characteristics behind $\mu_{i}{ }^{w}$ and $v_{i j}{ }^{w}$ may lead to biased estimates of the coefficients. As in the previous subsection, I address this problem by controlling for fixed effects (identifying the slopes through within-individual variation) and including as explanatory variables the same set of dummies used to track workers' changes of employer.

Table 4 reports the most relevant estimates from different versions of equation (2) when training is measured as the cumulated number of training events carried out during the previous sample periods. ${ }^{12}$ Model I presents the results of estimating returns to training without accounting for promotion achievement. The estimates are relatively close to those obtained by Booth and Bryan (2007) for the 1998-2000 waves of the same data. Male and female workers are expected to obtain, respectively, 1.4 percent and 1.6 percent wage increases from each training event with their current employers. These figures are virtually identical when we control for promotion (Model III). The interaction between training and promotion (Model IV) is positive and marginally significant only in the case of men, the expected returns to training being some 1 percent higher after obtaining a promotion. Training events with previous employers produce more unbalanced results: while women are expected to obtain 1.9 percent higher wages from them, the estimated effect for men is only 0.5 percent and not statistically significant. Again, these effects are quite similar (2.1 percent and 0.7 percent, respectively) when we control for promotion. Finally, the interaction between training received with previous employers and promotion is not statistically significant for either gender. In sum, a large part of returns to training is independent of promotion attainment, although the interaction between them for the sample of men is positive and significant at 10 percent. Regarding wage increases upon promotion, Model II reports figures of 6.8 percent for both male and female workers. These figures are reduced to 6.5 percent and 6.2 percent when we control for training. The significant interaction estimated in Model IV also implies that males' returns to promotion somewhat depend on training received with current employer. Their wage increase upon promotion is expected to be 1 percent higher with each additional training event carried out, starting from a 5.1 percent for a man with no training events in his record. Voluntary quits to better jobs seem to reward workers less than promotions in the short run: expected wage increases upon

${ }^{12}$ Although the BHPS records about up to three training events since 1998, it is only recorded up to one event in the first seven waves of the sample. Therefore, I count at most one event each year. 


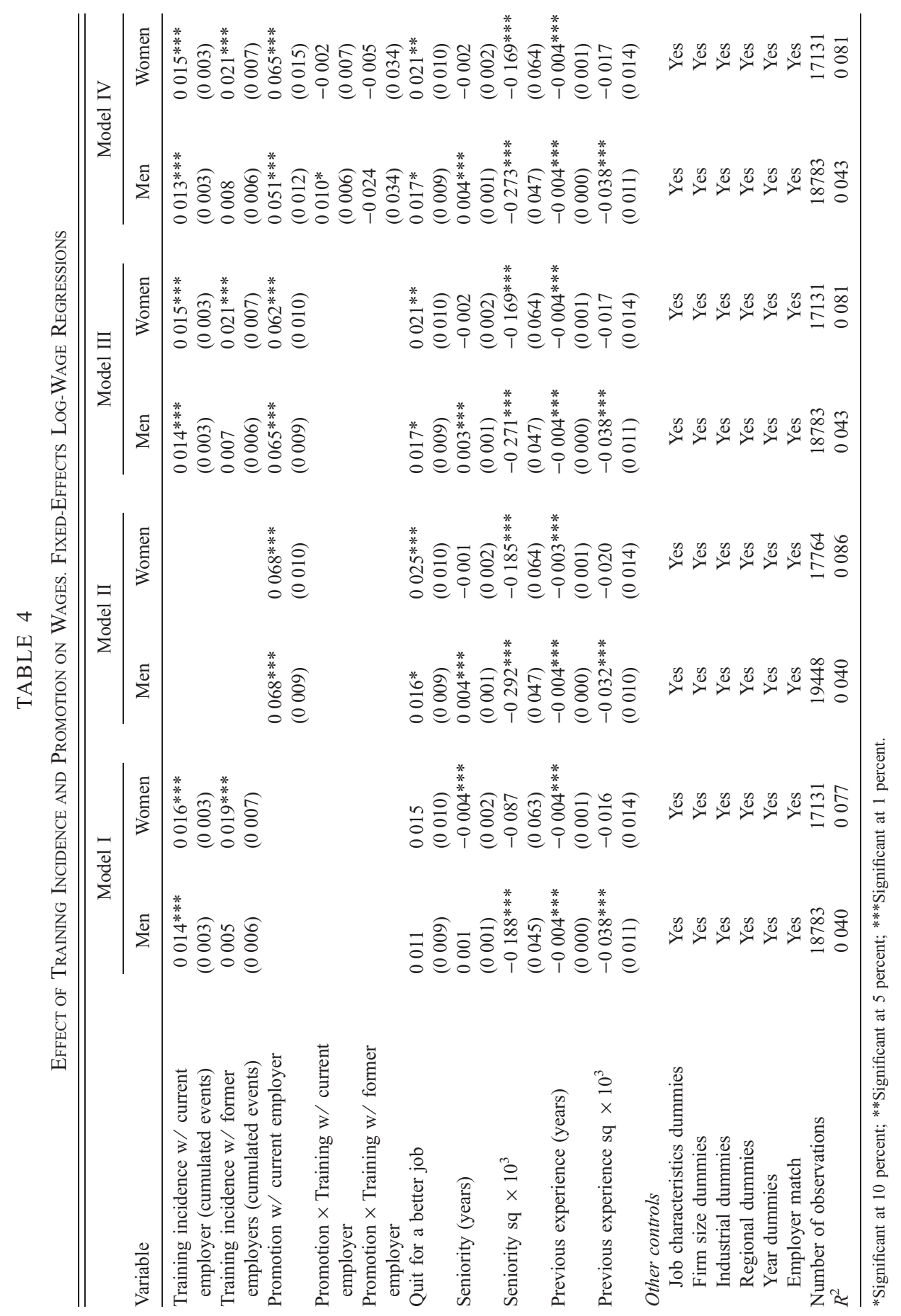


quitting are only around 2 percent, with slightly higher figures for women than for men. ${ }^{13}$

The two types of analysis presented above yield mixed results. The evidence for male workers is consistent with a concept of promotions as mechanisms to induce effort. Men increase significantly their promotion prospects by working longer hours, not by participating in training events. Furthermore, their returns to training remain virtually unchanged when we control for promotion achievement. Only the complementary effect of promotion and current-employer training on wages (their interaction is significant at 10 percent) is at odds with a view of promotions independent of job-related training for this group of workers. For the sample of women, the results suggest that allocation of their skills, rather than incentives, is behind their career progress. First, the training carried out by female workers has a positive impact on their probability of both promotion and quit for a better job. Second, they obtain significant wage returns to training events with previous employers, similar in magnitude to the returns attained from current-employer training. Finally, their returns to training are independent of promotion achievement, suggesting that their promotion was not purposely devised to induce their training.

These findings suggest that differences between men and women in labor market performance cannot be explained in terms of a single driver of career progress, as it has been traditionally done in the literature. Rather, the determinants of career progress seem to be different for male and female workers. Career moves of men appear to be more related to internal labor markets structures, with an important role of effort and a higher relevance of the training carried out within the firm. Conversely, women's moves are more closely related to the market value of their skills, as shown by the fact that their training with previous employers affects positively their wages with prospective ones.

\section{Additional Evidence}

The results presented so far give little support to a theory of promotion schemes as incentives for firm-specific training. To gain insight in this respect, it is necessary to split the training variable according to its firm-specific or general-purpose nature. On a different note, the reported sex differences may be due to the attainment of different levels of education or to the selection of

\footnotetext{
${ }^{13}$ The finding that promotions yield higher wage increases than quits for better jobs can be explained by the loss of firm-specific human capital imposed by a separation, which may be compensated in the long run by a better use of the worker's skills. Long-term cumulative wage growth has been estimated to be much more affected by separations than by within-employer mobility, especially for young workers (McCue 1996; Topel and Ward 1992).
} 
men and women into different occupations and different types of training programs. In this section, I address these two different types of concerns by presenting additional evidence. First, the relationship between training and promotion is analyzed for different categories of training. Then, I investigate the extent to which the reported results hold when the analysis is done independently for different education and occupation groups.

Different Types of Training. The data recorded in the BHPS concerning jobrelated training of individuals includes the following five questions about the aim of the training received:

Was any of this training (READ OUT):

1. Induction training to help you to do your current job?

2. To improve your skills in your current job?

3. To increase your skills in your current job for example by learning new technology?

4. To prepare you for a job or jobs you might do in the future?

5. To develop your skills generally?

The answers to the last of these questions can be used to explore the relationship between training and promotion in terms of Becker's division of human capital into general-purpose and firm-specific types. ${ }^{14}$ This distinction is suitable to evaluate how the three proposed views of promotions fit the data. If task assignment is solely determined by (expected) skills of workers, promotion prospects must be similarly affected by general and specific training to the extent that both are equally useful at higher-level jobs. Conversely, if promotions are a reward for workers' effort in learning firm-specific skills, (1) the provision of specific training must be especially related to promotion chances, (2) the observed returns to specific training must decrease importantly when promotion is controlled for, and (3) the effect of the interaction between specific training and promotion on wages must be positive. Lastly, if promotion schemes are devised to encourage effort, neither general nor firm-specific human capital must be relevant for promotion attainment and returns to training and promotion must be independent.

Panel A of Table 5 shows the relevant results of considering independently general and specific training in the estimation of equation (1). The estimated odds ratios suggest that unobserved heterogeneity especially biases the effect of general training for the sample of men. In accordance with the incentivesoriented view, promotion prospects of men are independent of either general

\footnotetext{
${ }^{14} \mathrm{I}$ interpret as firm specific all the training that the worker declared it was not aimed to develop his skills generally.
} 
TABLE 5

Effect of Different Types of Training on Career Progress (Versus no Career Progress).

OdDS RATIOS $^{\mathrm{a}}$

\begin{tabular}{|c|c|c|c|c|c|c|c|c|}
\hline \multirow[b]{3}{*}{ Variable } & \multicolumn{4}{|c|}{ Promotions } & \multicolumn{4}{|c|}{ Quits to better job } \\
\hline & \multicolumn{2}{|c|}{ Logit RE } & \multicolumn{2}{|c|}{ Logit FE } & \multicolumn{2}{|c|}{ Logit RE } & \multicolumn{2}{|c|}{ Logit FE } \\
\hline & Men & Women & Men & Women & Men & Women & Men & Women \\
\hline \multicolumn{9}{|c|}{ Panel A: General and Specific skills } \\
\hline \multicolumn{9}{|c|}{ Incidence last year } \\
\hline General skills & $1.275^{* * *}$ & $1.287 * * *$ & 0.972 & 1.145 & 0.947 & $1.206^{* *}$ & 0.973 & $1.261 * *$ \\
\hline Specific skills & 1.046 & $1.327 * *$ & 0.961 & $1.352 * *$ & 0.969 & 1.115 & 1.122 & 1.168 \\
\hline \multicolumn{9}{|l|}{ Days last year } \\
\hline General skills & 1.000 & $1.003 * * *$ & 0.999 & $1.004 * * *$ & $0.997 * *$ & 1.001 & $0.995 * *$ & 1.001 \\
\hline Specific skills & 0.999 & 1.004 & 0.999 & 0.998 & 1.003 & 0.999 & 1.002 & 0.996 \\
\hline \multicolumn{9}{|c|}{ Incidence last 2 years } \\
\hline General skills & $1.360 * * *$ & $1.332 * * *$ & 1.063 & 1.141 & 0.905 & $1.136^{*}$ & 1.020 & 1.135 \\
\hline Specific skills & 0.995 & 1.142 & 0.964 & 1.152 & 0.963 & 1.032 & 1.165 & 1.129 \\
\hline \multicolumn{9}{|l|}{ Days last year } \\
\hline General skills & $1.001 * *$ & $1.002 * * *$ & 1.000 & $1.004 * * *$ & $0.997 * *$ & 1.001 & $0.995 * * *$ & 1.000 \\
\hline Specific skills & 0.999 & $1.004 * *$ & 1.000 & 1.006 & 1.002 & $1.004^{* *}$ & 1.001 & 1.001 \\
\hline \multicolumn{9}{|c|}{ Panel B: All four types of skills } \\
\hline \multicolumn{9}{|c|}{ Incidence last year } \\
\hline Induction & 1.017 & 0.957 & 0.921 & 0.963 & 1.056 & $0.763^{* *}$ & 0.876 & 0.788 \\
\hline Current-job skills & 1.048 & 1.147 & & $1.337 * *$ & $0.758^{* *}$ & 0.939 & 0.833 & 0.925 \\
\hline Future-job skills & $1.234 * *$ & $1.432 * * *$ & 1.115 & $1.245^{*}$ & 0.885 & 0.981 & 0.855 & 1.006 \\
\hline General skills & 1.085 & 0.907 & 1.013 & $0.784 *$ & $1.274 * *$ & $1.351^{* *}$ & $1.354^{*}$ & $1.355^{* *}$ \\
\hline \multicolumn{9}{|c|}{ Incidence last 2 years } \\
\hline Induction & 1.014 & 0.984 & 0.863 & 0.925 & 0.984 & 0.894 & 0.866 & 1.069 \\
\hline Current-job skills & 1.038 & $1.287 * *$ & 0.860 & $1.548 * * *$ & $0.777 * * *$ & 0.949 & $0.724 * *$ & 0.807 \\
\hline Future-job skills & $1.253 * * *$ & $1.279 * * *$ & 1.084 & 1.130 & 1.037 & 1.111 & 1.107 & $1.313^{*}$ \\
\hline General skills & 1.139 & 0.940 & 1.169 & 0.791 & 1.069 & 1.154 & 1.226 & 1.115 \\
\hline
\end{tabular}

${ }^{\text {a}}$ All regressions include the same control variables of the analogous regressions summarized in Table 2.

*Significant at 10 percent; **Significant at 5 percent; ***Significant at 1 percent.

or specific training when we control for fixed effects. The evidence is much less conclusive for the sample of women: in terms of training days only general skills matter for promotion, while in terms of training events specific skills play a more relevant role. Female workers are more likely to quit for better jobs when they receive general training whilst the effect is reversed for the case of male employees. These two findings, however, are not stable across different measures of training.

Table 6 shows the results of including different measures of general and firm-specific training in the estimation of equation (2). Interestingly, while male workers only obtain significant wage returns to (general or specific) training carried out with their current employers, women get significant wage returns to general training, around 2 percent per event, independently of the firms employing them during the training. 


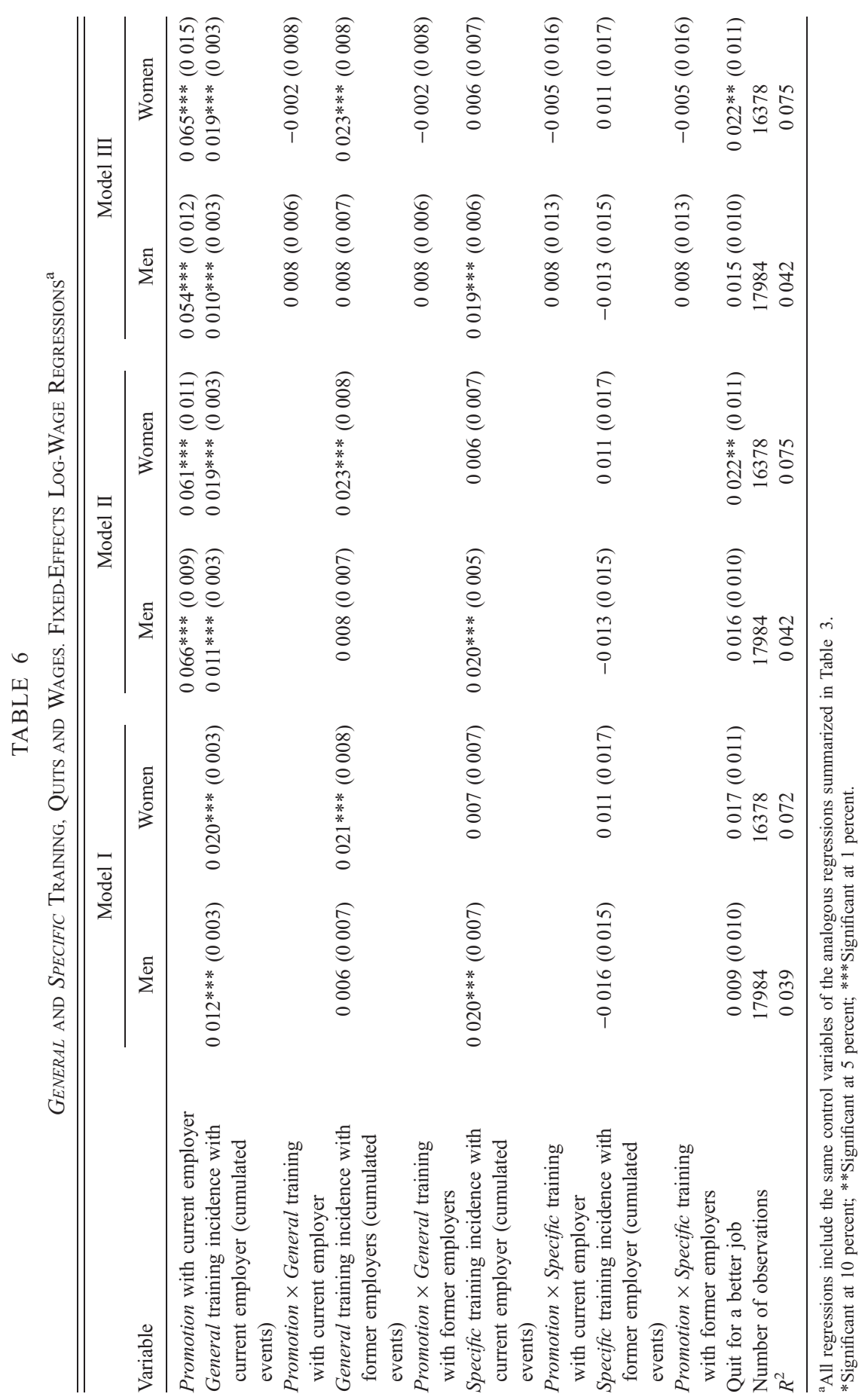


These findings reinforce the idea of structural differences in the career patterns of male and female workers, with women's possibilities of progress more attached to the market value of their skills and men's chances more linked to their employer firms' internal rules. The incentives-to-invest theory of promotions is consistent with the significant effect of firm-specific training on promotion that is observed for the sample of women in Table 5. However, the figures corresponding to the effect of specific training on wages across the three specifications of Table 6 strongly discredit this view: returns to specific training with the current employer (about 2.1 percent for male workers and non-significant 0.9 percent for females) do not vary when we control for promotion receipt, and the estimated interactions between employer-specific training and promotion in the wage equation are not statistically significant.

The information about the aim of the training included in the BHSP is also useful to check the robustness of the results of previous section. Men and women could tend to select into different types of training. In particular, women could be more likely to enroll in future-jobs skills programs and this, in turn, could especially increase their chances of promotion. ${ }^{15}$ To address this issue, Panel B of Table 5 shows the effect of different types of training on career progress. ${ }^{16}$ The effect of future-job training is strongly affected by unobserved heterogeneity and shrinks to non-significant levels in the fixed-effects specifications for both genders. This suggests that selection into future-job training programs does not bias the results. Furthermore, the average participation rates displayed in the Appendix do not show large differences in the type of training pursued by men and women. Results from Panel B of Table 5 also show that current-job training has an especially large and significant effect on promotion for the sample of women. The participation rate in this particular category of programs is in fact slightly larger for men (see Appendix). Results concerning different aims of training must be nonetheless interpreted with caution, since the categories are not mutually exclusive. Multi-collinearity problems are likely to arise from the high correlation between the incidence of future- and current-job-skills training $(\rho=0.65)$. Furthermore, it is not possible to assign training days to different categories, and therefore the stability of the results across different measures of training can not be tested.

Differences across Education Levels and Occupations. Education is a potentially relevant factor affecting the relationship between training and pro-

\footnotetext{
${ }^{15}$ I thank an anonymous referee for suggesting this robustness test.

${ }^{16}$ Categories 2 (improving skills) and 3 (increasing skills) have been collapsed into a single category, as they are difficult to distinguish in intuitive terms.
} 
motion. Schooling and training can be complements if, for example, educated workers have higher ability to learn (Gibbons and Waldman 2006). Likewise, education and training can be substitutes if they involve similar types of skills. In this last case, lower-educated workers would get higher increase in promotion chances after training. This second possibility is particularly relevant, since women tend to attain lower education levels than men (see Appendix). Therefore, their higher effect of training on promotion probability could be just a composition effect. To deal with this issue, I analyzed the relationship between training and career progress separately for five education attainment levels: less than secondary education (no education), basic certificate of secondary education (CSE), ordinary-level general certificate of education (O-Level), advanced-level general certificate of education (A-Level), and University Degree. Panel A of Table 7 shows the results. The figures do not show a clear pattern of either complementarity or substitution between education and training in promotion achievement. The negative effect found for the lowest education group could suggest complementary effects when starting from very low levels of schooling, but this result is far from significant. Furthermore, $\chi^{2}$ tests of pair-wise differences between the estimated effects for the various levels of education did not produce any significant difference in coefficients. With respect to quits for better jobs, the effect of training is also irregularly

\section{TABLE 7}

Effect of Last Year Training Incidence on the Probabilities of Career Progress (Versus no Career Progress) for Different Occupation Education Groups. Independent

VARIABLE: INCIDENCE LAST YEAR ${ }^{a}$

\begin{tabular}{|c|c|c|c|c|c|c|c|c|}
\hline & \multicolumn{4}{|c|}{ Promotions } & \multicolumn{4}{|c|}{ Quits to better job } \\
\hline & \multicolumn{2}{|c|}{ Logit RE } & \multicolumn{2}{|c|}{ Logit FE } & \multicolumn{2}{|c|}{ Logit RE } & \multicolumn{2}{|c|}{ Logit FE } \\
\hline & Men & Women & Men & Women & Men & Women & Men & Women \\
\hline \multicolumn{9}{|c|}{ Panel A: Education groups } \\
\hline No education & $1.486^{*}$ & $1.543^{* *}$ & 0.883 & 0.954 & $1.458^{* *}$ & 1.122 & 1.528 & 1. 069 \\
\hline CSE & $2.048 * * *$ & 1.202 & 1.327 & 1.507 & 0.789 & 1.167 & 1.386 & 1.209 \\
\hline O-Level & 1.144 & $1.367 * * *$ & 1.068 & $1.314 *$ & 0.844 & 1.141 & $0.726^{* *}$ & 1.137 \\
\hline A-Level & $1.454 * * *$ & $1.514 * * *$ & 1.023 & 1.110 & 0.957 & $1.681 * * *$ & 1.118 & $1.727 * * *$ \\
\hline University degree & 1.140 & 1.066 & 1.022 & 1.200 & 1.014 & 0.931 & $1.364 *$ & 1.051 \\
\hline \multicolumn{9}{|c|}{ Panel B: Occupation groups } \\
\hline Managers & 1.045 & 1.116 & 0.982 & 1.183 & 0.772 & 0.985 & 1.545 & 1.450 \\
\hline Technicals \& Professionals & 1.086 & 1.034 & 0.801 & 0.855 & 0.975 & 0.968 & 1.057 & 0.848 \\
\hline Clerks \& Crafts & $1.450 * * *$ & $1.437 * * *$ & 1.241 & $1.342^{*}$ & 0.891 & 1.172 & 0.855 & 1.225 \\
\hline Sales \& Services & $1.415^{* *}$ & $1.580^{* * *}$ & 1.042 & $1.623^{* *}$ & 1.153 & $1.382 * * *$ & 1.375 & $1.413 * *$ \\
\hline Operatives \& Others & $1.484 * * *$ & 1.253 & 1.175 & 0.788 & 1.072 & $1.428 * *$ & 1.072 & 1.457 \\
\hline
\end{tabular}

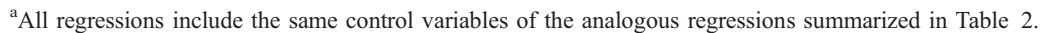

*Significant at 10 percent; **Significant at 5 percent; ***Significant at 1 percent. 
distributed across education levels. Women holding an A-level degree are especially able to complement their high-school skills with job-related training and improve their career prospects in alternative employers.

The sex differences in career drivers portrayed hitherto could be also due the selection of men and women into different types of occupations. The fact that workers of different sex tend to work in different occupations is well known (Altonji and Blank 1999; Polachek 1981). Furthermore, different types of jobs may require different amounts of job-related training and it is possible that the stronger link between training and promotion found for women is caused by the particular nature of their occupations. To address this point, I consider the relationship between training and career progress separately for different "initial occupation" groups. Individuals are assigned to one of five different groups according to their occupation in the first year in the sample ${ }^{17}$ : "Managers," "Technical and Professional," "Clerks and Crafts," "Sales and Service", and "Operatives and Other Similar Occupations." Women are over-represented in the "Sales and Services" group and under-represented in "Managers" and "Operatives and Others" categories (see Appendix).

Panel B of Table 7 shows the estimated effect of training on the odds of obtaining a promotion for the mentioned groups. The different results found for men and women in the foregoing analyses are not a mere composition effect due to selection into different occupations. After controlling for unobserved heterogeneity, the estimated effect of training on promotion is larger for women than for men in four of the five occupation groups. However, the general results are clearly driven by the large and significant effect found for women in "Sales and Services" and, to a lower extent, in "Clerks and Crafts." Additional analysis shows that these coefficients are significantly larger than the ones corresponding to other occupations. Furthermore, if we exclude the Sales and Services category from the sample of women, the effect of training on promotion is not significant any more. These results hint that "Clerks and Crafts" and "Sales and Services" are the type of intermediate categories for which training helps women in their future career progress. In principle, these findings may indicate that women more frequently than men choose jobs where training matters for career progress. Then, female overrepresentation in "Sales and Services" could be (partially) due to jobs in this category being more likely to meet such requirement. Note, however, that training does not affect the probability of promotion of male workers in "Sales and Services" jobs, but only that of women. Consequently, although

${ }^{17}$ The alternative to using "initial occupation" is splitting the sample according to actual occupations. This option provides much less within-group variation for identification in the fixed-effect model. More importantly, variations in actual occupation are clearly endogenous to promotion and quit for better job. 
self-selection of women into jobs where promotion depends on training cannot be ruled out, the selection process would involve some specific jobs within the "Sales and Services" category, not jobs from this category in general.

In sum, we can say that the significant relationship between training and promotion found for women in the previous section is not caused by either selection into different types of training programs or schooling-substitution effects. Occupation of the worker, however, plays a relevant role as moderator of the relationship. Significant impact of training on promotion is only found for female workers starting in "Sales and Services" and "Clerks and Crafts" categories.

\section{Discussion and Conclusion}

The most relevant results presented in this article are the gender differences found in the relationship between training and career moves. Females' career progress is related to their training activities. Such a result is not observed for the sample of men. Moreover, "doing overtime work," a likely proxy of employees' effort and commitment to the organization, has a significant effect on promotion prospects only for male workers. The analysis also shows that men obtain significant wage returns from (general or specific) training carried out with their current employers and women obtain significant returns from all types of general-purpose training. These pieces of evidence suggest that theories of human capital accumulation and efficiency in the allocation of skills explain well women's career moves, especially if they work in "clerks and crafts" or "sales and services" occupations. In the case of men's careers, promotions seem to play a role as providers of incentives to work hard.

Asymmetric Information. The interpretation of these results could change if we consider the information privately held by workers about their own ability, their motivation or, more generally, their attachment to the labor market (Spence 1973). It is particularly plausible that participation in training programs is a relevant signal of attachment to the labor market for women but not for men. First, since women are more heterogeneous in their probability of leaving the market, signaling labor market attachment may be particularly important for them. Second, if women are more constrained than men in their choices on working hours, they may find it more difficult to signal their labor market attachment through alternative mechanisms such as overtime work. Conversely, by investing in training women could be signaling their commitment to stay in the labor force because the investment only pays off if they participate. In that case, the increased promotion probability that they obtain after training would not be due to their superior productivity, but to the signal 
sent to employers that they are committed not to leave the labor market. Such interpretation of results, however, would require the relationship between training and labor market attachment to be stronger for women than for men. To explore this issue, I analyzed the determinants of labor market exit including jobrelated training as the key explanatory variable. The results show similar negative effects of training on labor market exit probability for men and women. This suggests that the potential value of training as a signal is similar for both gender groups. Therefore, this type of signaling does not seem to be behind the observed differences in the relationship between training and promotion.

Theories that stress the strategic role of promotions when current employers have private information about the ability of their workers (Bernhardt 1995; Milgrom and Oster 1987; Waldman 1984; Zábojník and Benhardt 2001) also provide an alternative interpretation for the main results of this article. According to this view, informational advantage allows employers to pay their tenured workers below their current productivity. This is because they only match outside wage offers of employees whose productivity exceeds such offer. As a result, alternative employers only offer wages associated with workers' minimum expected productivity. Furthermore, in the attempt to preserve private information, employers fail to promote some of the workers who are potentially more productive in higher-level jobs. The reason is that promotion reveals that the upgraded workers are apt enough for the new job, increasing their minimum expected productivity and, therefore, their wages. In this setting, the relationship between training and promotion will be positive as long as the current employer is actively involved in the provision of training and this can be observed by other potential employers (Bernhardt 1995: 335). By providing training to a worker, the employer reveals to the market that the employee has (at least) the ability to make the investment profitable. This generates a positive update in the market's minimum expected productivity of the worker which, in turn, leads to a wage increase. Then, promotion becomes less costly after training, as it discloses less information and leads to a smaller wage increase. These asymmetric information-related effects may be more prevalent for women if they are "less visible" workers whose skills are more difficult to ascertain by potential employers (Milgrom and Oster 1987).

Theories of asymmetric information, however, imply further predictions that are hard to reconcile with some of the evidence presented in this paper. First, when training and promotion occur simultaneously, the joint effect on wages is expected to be lower than when awarded in isolation. This is not observed for either gender group (see Table 4). Second, wage increase upon promotion should be higher for women if they are "less visible" workers. Table 4 , however, shows very similar increases for both gender groups. Finally, since low visibility is associated to low education (Milgrom and Oster 1987), uneducated workers are 
expected to obtain larger promotion chances after training. Again, the results shown in Table 6 do not support this prediction. Overall, the significant impact of training on women's career progress is better explained in terms of the corresponding increase in human capital than in terms of its potential signaling effect.

Concluding Remarks. Women's career moves are linked to participation in training programs while those of men are more related to measures of effort and commitment to the organization. These systematic differences in antecedents of career progress are possibly related with women's lower expected probability of staying in the labor force and lower expected working hours in the future. Long-term labor relationships that typically characterize internal labor markets involve high employee commitment, specific human capital, and deferred compensation structures that punish early voluntary turnover. Expected differences in labor market attachment or future working hours may lead to the selection of women into more spot-market oriented employment relationships. This, in turn, makes career progress of women more dependent on the current value of their skills. A "higher expected turnover" argument is used by Goldin (1986) to explain why female operatives in manufacturing in 1890 were four times as likely as males to be paid on piece rate schemes instead of deferred payment. Its rationale can be extended mutatis mutandis to explain the observed gender differences in determinants of career moves. More generally, the findings of this article have important consequences for the future development of theories of career dynamics and for models connecting them to gender issues. Narrow models with tightly defined determinants of promotions are not accurate. Instead, future research about career processes that lead to female disadvantage in earnings must consider the existence of different possible career paths with well-differentiated rules of progress. In a similar vein, models that analyze the incentive role of promotions and those that deal with the dynamics of task-assignment within organizations must be combined if they are to be applied to a diverse population of workers.

\section{REFERENCES}

Ahn, Seung Chan, Young Hoon Lee, and Peter Schmidt. 2001. "GMM Estimation of Linear Panel Data Models with Time-varying Individual Effects." Journal of Econometrics 101(2): 21955.

Altonji, Joseph, and Rebecca Blank. 1999. "Race and Gender in the Labor Market." In Handbook of Labor Economics (Vol. 3C), edited by Orley Ashenfelter and David Card, pp. 3143 259. Amsterdam: Elsevier Science Press.

Arellano, Manuel, and Stepehen Bond. 1991. "Some Specification Tests for Panel Data: Monte Carlo Evidence and Application to Employment Equations." Review of Economic Studies 58(2): 27798.

Ariga, Kenn, Yasushi Ohkusa, and Giorgio Brunello. 1999. "Fast Track: Is it in the Genes? The Promotion Policy of a Large Japanese Firm." Journal of Economic Behavior and Organization 38(4): 385 402. 
Baker, George P., Michael Gibbs, and Bengt Holmstrom. 1994. "The Internal Economics of a Firm: Evidence from Personnel Data." Quarterly Journal of Economics 109(4): 881919.

Belzil, Christian, and Michael Bognanno. 2004. "The Promotion Dynamics of American Executives." Discussion Paper No. 1003. Institue for the Study of Labor (IZA).

Bernhardt, Dan. 1995. "Strategic Promotion and Compensation." Review of Economic Studies 62(2): 315 39.

Booth, Alison L., and Mark L. Bryan. 2007. "Who Pays for General Training in Private Sector Britain?" Research in Labor Economics 26: 85123.

, Marco Francesconi, and Jeff Frank. 2003. "A Sticky Floors Model of Promotion, Pay and Gender." European Economic Review 47(2): 295322.

Carmichael, Lorne. 1983. "Firm-Specific Human Capital and Promotion Ladders." Bell Journal of Economics 14(1): 25158.

Chamberlain, Gary. 1980. "Analysis of Covariance with Qualitative Data." Review of Economic Studies 47(1): 22538.

Chan, William. 1996. "External Recruitment versus Internal Promotion." Journal of Labor Economics 14(4): 55570.

Doeringer, Peter B., and Michael J. Piore. 1971. Internal Labor Markets and Manpower Analysis. Lexington, MA: Heath Lexington Books.

Dohmen, Thomas J., Ben Kriechel, and Gerard A. Pfann. 2004. "Monkey Bars and Ladders: The Importance of Lateral and Vertical Mobility in Internal Labor Market Careers." Journal of Population Economics 17(2): 193228.

Fairburn, James A., and James M. Malcomson. 2001. "Performance, Promotion and the Peter Principle." Review of Economic Studies 68(1): 4566.

Francesconi, Marco. 2001. "Determinants and Consequences of Promotions in Britain." Oxford Bulletin of Economics and Statistics 63(3): 279310.

Gibbons, Robert, and Michael Waldman. 1999a. "Careers in Organizations: Theory and Evidence." In Handbook of Labor Economics (Vol.3B), edited by Orley Ashenfelter and David Card, pp. 2373437. Amsterdam: Elsevier Science Press.

, and 1999b. "A Theory of Wage and Promotion Dynamics inside Firms." Quarterly Journal of Economics 114(4): 132158.

, and .2006. "Enriching a Theory of Wage and Promotion Dynamics inside Firms." Journal of Labor Economics 24(1): 59107.

Goldin, Claudia. 1986. "Monitoring Costs and Occupational Segregation by Sex: A Historical Analysis." Journal of Labor Economics 4(1): 127.

Heckman, James, and George Borjas. 1980. "Does Unemployment Cause Future Unemployment?" Economica 47(187): 24783.

Hersch, Joni, and W. Kip Viscusi. 1996. "Gender Differences in Promotions and Wages." Industrial Relations 35(4): 46172.

Kahn, Charles, and Gur Huberman. 1988. "Two-sided Uncertainty and Up-or-Out Contracts." Journal of Labor Economics 6(4): 42344.

Lazear, Edward P., and Sherwin Rosen. 1981. "Rank-Order Tournaments as Optimum Labor Contracts." Journal of Political Economy 89(5): 84164.

, and . 1990. "Male Female Wage Differentials in Job Ladders." Journal of Labor Economics 8(1): S106 23.

McCue, Kristin. 1996. "Promotions and Wage Growth." Journal of Labor Economics 14(2): 175209.

Milgrom, Paul, and Sharon Oster. 1987. "Job Discrimination, Market Forces, and the Invisibility Hypothesis." Quarterly Journal of Economics 102(3): 45376.

Perfect, D., and K. Hurrell. 2003. Pay and Income: Women and Men in Britain Series. London: Equal Opportunities Commission.

Pergamit, Michael R., and Jonathan R. Veum. 1999. "What Is a Promotion?" Industrial and Labor Relations Review 52(4): 581601.

Polachek, Solomon W. 1981. "Occupational Self-Selection: A Human Capital Approach to Sex Differences in Occupational Structure." Review of Economics and Statistics 63(1): 6069. 
Prendergast, Canice. 1993. "The Role of Promotion in Inducing Specific Human Capital Acquisition." Quarterly Journal of Economics 108(2): 52334.

Seltzer, Andrew, and David Merrett. 2000. "Personnel Policies at the Union Bank of Australia: Evidence from the 18881900 Entry Cohorts." Journal of Labor Economics 18(4): 573613.

Sicherman, Nachum, and Oded Galor. 1990. "A Theory of Career Mobility." Journal of Political Economy 98(1): 16992.

Spence, Michael. 1973. "Job Market Signaling.” Quarterly Journal of Economics 87(3): 35574.

Taylor, Marcia Freed (ed.), with John Brice, Nick Buck, and Elaine Prentice-Lane. 2001. British Household Panel Survey User Manual. Colchester: University of Essex.

Topel, Robert H., and Michael P. Ward. 1992. "Job Mobility and the Careers of Young Men." The Quarterly Journal of Economics 107(2): 43979.

Treble, John, Edwin V. Gameren, Sarah Bridges, and Tim Barmby. 2001. "The Internal Economics of the Firm: Further Evidence from Personnel Data." Labor Economics 8(5): 53152.

Waldman, Michael. 1984. "Job Assignments, Signalling and Efficiency." Rand Journal of Economics 15(2): 25567.

Wooldridge, Jeffrey M. 2002. Econometric Analysis of Cross Section and Panel Data. Cambridge, MA: MIT Press.

Zábojník, Ján, and Dan Benhardt. 2001. "Corporate Tournaments, Human Capital Acquisition and the Firm Size-Wage Relation.” Review of Economic Studies 68(3): 693716.

\section{APPENDIX}

Population Means of Relevant Variables

\begin{tabular}{|c|c|c|c|c|c|c|}
\hline \multirow[b]{2}{*}{ Variable } & \multicolumn{3}{|c|}{ Men } & \multicolumn{3}{|c|}{ Women } \\
\hline & All & Trained & Not-trained & All & Trained & Not-trained \\
\hline$N$ & 19140 & 6522 & 12618 & 18000 & 5758 & 12242 \\
\hline Promotion receipt & 0.080 & 0.124 & 0.057 & 0.064 & 0.107 & 0.043 \\
\hline Quit for a better job & 0.089 & 0.092 & 0.088 & 0.085 & 0.101 & 0.078 \\
\hline Training incidence & 0.341 & & & 0.320 & & \\
\hline Induction training & 0.063 & 0.184 & & 0.064 & 0.200 & \\
\hline Current-job training & 0.237 & 0.699 & & 0.220 & 0.690 & \\
\hline Future-job training & 0.198 & 0.583 & & 0.179 & 0.566 & \\
\hline General training & 0.275 & 0.812 & & 0.275 & 0.824 & \\
\hline Training days & 5.728 & 18.472 & & 5.610 & 19.561 & \\
\hline Age & 36.196 & 34.963 & 36.833 & 36.022 & 34.903 & 36.548 \\
\hline Years of seniority & 4.601 & 3.866 & 4.981 & 4.039 & 3.351 & 4.363 \\
\hline Job market experience & 9.547 & 8.128 & 10.281 & 9.712 & 8.962 & 10.065 \\
\hline Temporary & 0.038 & 0.018 & 0.048 & 0.055 & 0.024 & 0.070 \\
\hline Fixed-term & 0.028 & 0.027 & 0.028 & 0.026 & 0.037 & 0.021 \\
\hline Part-time & 0.057 & 0.035 & 0.069 & 0.364 & 0.242 & 0.421 \\
\hline Overtime & 0.585 & 0.625 & 0.565 & 0.384 & 0.495 & 0.332 \\
\hline Receiving bonus & 0.405 & 0.467 & 0.373 & 0.290 & 0.334 & 0.269 \\
\hline Union coverage & 0.464 & 0.464 & 0.371 & 0.387 & 0.505 & 0.331 \\
\hline Union membership & 0.260 & 0.303 & 0.238 & 0.220 & 0.305 & 0.180 \\
\hline
\end{tabular}


APPENDIX (cont.)

\begin{tabular}{lccccccc}
\hline & \multicolumn{3}{c}{ Men } & & \multicolumn{3}{c}{ Women } \\
\cline { 2 - 3 } Variable & All & Trained & Not-trained & & All & Trained & Not-trained \\
\hline Hourly wage (£ of 1998) & 8.754 & 9.835 & 8.195 & & 6.372 & 7.340 & 5.915 \\
Managers & 0.143 & 0.156 & 0.137 & & 0.075 & 0.094 & 0.066 \\
Professors and technicals & 0.138 & 0.249 & 0.138 & & 0.154 & 0.255 & 0.106 \\
Clerks and crafts & 0.314 & 0.305 & 0.319 & & 0.330 & 0.305 & 0.342 \\
Sales and service & 0.123 & 0.121 & 0.124 & & 0.291 & 0.258 & 0.306 \\
Operative and others & 0.244 & 0.169 & 0.283 & & 0.150 & 0.088 & 0.180 \\
University degree & 0.221 & 0.295 & 0.183 & & 0.151 & 0.222 & 0.117 \\
A-Level (secondary) & 0.235 & 0.271 & 0.216 & & 0.199 & 0.247 & 0.177 \\
O-Level (secondary) & 0.276 & 0.265 & 0.282 & & 0.358 & 0.345 & 0.364 \\
CSE (secondary) & 0.072 & 0.056 & 0.080 & & 0.071 & 0.051 & 0.080 \\
No education & 0.196 & 0.114 & 0.239 & & 0.221 & 0.134 & 0.261 \\
\hline
\end{tabular}

